\title{
Promoting Understanding of Chemical Representations: Students' Use of a Visualization Tool in the Classroom
}

\author{
Hsin-Kai Wu, Joseph S. Krajcik, Elliot Soloway \\ School of Education, University of Michigan, 610 East University, 4009 SEB, Ann Arbor, \\ Michigan 48109-1259
}

Received 28 June 2000; accepted 20 April 2001

\begin{abstract}
Many students have difficulty learning symbolic and molecular representations of chemistry. This study investigated how students developed an understanding of chemical representations with the aid of a computer-based visualizing tool, eChem, that allowed them to build molecular models and view multiple representations simultaneously. Multiple sources of data were collected with the participation of 71 eleventh graders at a small public high school over a 6-week period. The results of pre- and posttests showed that students' understanding of chemical representations improved substantially $(p<.001$, effect size $=2.68$ ). The analysis of video recordings revealed that several features in eChem helped students construct models and translate representations. Students who were highly engaged in discussions while using eChem made referential linkages between visual and conceptual aspects of representations. This in turn may have deepened their understanding of chemical representations and concepts. The findings also suggest that computerized models can serve as a vehicle for students to generate mental images. Finally, students demonstrated their preferences of certain types of representations and did not use all types of threedimensional models interchangeably. (c) 2001 John Wiley \& Sons, Inc. J Res Sci Teach 38: 821-842, 2001
\end{abstract}

\section{Introduction}

For decades chemistry educators and researchers have explored how to help students develop a conceptual understanding of chemical representations (Ben-Zvi, Eylon, \& Silberstein, 1986; Gabel, 1998; Keig \& Rubba, 1993; Kozma \& Russell, 1997). In this area of research three levels of representations in chemistry have been discussed: macroscopic, microscopic, and symbolic levels (Gabel, 1998; Johnstone, 1993). At the macroscopic level chemical processes are observable, for example, burning candles. At the microscopic level chemical phenomena are explained by the arrangement and motion of molecules, atoms, or subatomic particles. Chemistry at the symbolic level is represented by symbols, numbers, formulas, equations, and structures. Empirical studies (e.g., Ben-Zvi, Eylon, \& Silberstein, 1987; Ben-Zvi, Eylon, \& Silberstein, 1988; Griffiths \& Preston, 1992) have shown that understanding microscopic and

Correspondence to: H.-K. Wu; E-mail: hkwu@umich.edu

Contract grant sponsor: National Science Foundation; Contract grant number: NSF REC-9555719 
symbolic representations is especially difficult for students because these representations are invisible and abstract while students' thinking relies heavily on sensory information. In addition, without substantial conceptual knowledge and visual-spatial ability, students are unable to translate one given representation into another (Keig \& Rubba, 1993; Seddon \& Eniaiyeju, 1986).

To help students understand chemistry at the three levels, researchers have suggested a variety of instructional approaches, such as adapting teaching strategies based on the conceptual change model (Krajcik, 1991), integrating laboratory activities into class instruction (Johnstone \& Letton, 1990), using concrete models (Copolo \& Hounshell, 1995), and using technologies as learning tools (Barnea \& Dori, 1996; Kozma, Russell, Jones, Marx, \& Davis, 1996). Among these approaches, using concrete models and technologies as learning tools seems promising. For example, viewing dynamic and three-dimensional animations created by technological tools could help students learn to use microscopic and symbolic representations to describe and explain a chemical process (Williamson \& Abraham, 1995). Multiple linked representations provided by multimedia tools allow students to visualize the interactions among molecules and understand the related chemical concepts (Kozma et al., 1996). In addition, manipulating physical models promotes long-term understanding of molecules and atoms (Copolo \& Hounshell, 1995; Gabel \& Sherwood, 1980; Talley, 1973).

Although empirical studies have shown the value of using models and technological tools for promoting chemistry learning, little is understood about how computer-based models support students' learning in classrooms and what features in a technological tool facilitate students' representational skills. These skills include making translations among different types of representations and transforming a two-dimensional structure into a three-dimensional one. Moreover, although professional visualizing tools such as CAChe have been routinely used in chemistry (Crouch, Holden, \& Samet, 1996), none of these was designed for novice users at the high school level. Therefore, the purpose of this study is to investigate how high school students develop their understanding of chemical representations by using a visualization tool similar to that of a professional but designed for learners.

eChem, ${ }^{1}$ a chemistry visualizing tool, allows students to build molecular models and view multiple representations simultaneously. This study explored how, aided by eChem, students develop their ability to visualize chemical representations, whether they are able to make translations between these representations, and what features support them in doing so. The following questions guided this study: (a) Are students able to make translations among chemical representations? (b) What learning patterns do students demonstrate while translating chemical representations and constructing models by using eChem? We infer learning patterns from types of behaviors and verbal comments that students demonstrate when they use eChem, such as common strategies or models used by particular student groups. (c) As chemical representations are conceptual constructs and visual displays, how do students link conceptual and visual information of representations? (d) If students are able to demonstrate representational skills after the use of eChem, in what ways does eChem help them to do so?

The methods we employed are based on principles of design experiments as delineated by Brown (1992) and Collins (1999). Because this research took place in real classroom environments, we did not use random assignment of students or control groups. Instead, we gathered a variety of types of data to investigate the research questions. We realize that a learning environment involves various factors influencing students' learning, such as a teacher's pedagogical knowledge and collaboration between students, so it is impossible to separate the learning effects that resulted from the use of eChem from those that resulted from the contribution of other factors. 
Theoretical Background and Empirical Foundations

\section{Chemistry and Representations}

Chemical representations refer to various types of formulas, structures, and symbols used to represent chemical processes and conceptual entities (e.g., molecules and atoms). Chemical representations can be viewed as metaphors, models, and theoretical constructs of chemists' interpretation of nature and reality (Hoffman \& Laszlo, 1991). The drawing of molecular structures and the writing of chemical formulas are theory laden and meaning based, created to reflect the unification or construction of theories and experiments. For example, the structural formula of benzene has been changed because of a better understanding of electron resonance. Symbolic and microscopic representations currently used in chemistry evolved from phenomenological analogies of sensory experiences at the macroscopic level (Hoffman \& Laszlo, 1991). They allow chemists to have a common language for their joint inquiry (Nye, 1993) and serve as tools to conduct science investigations and communicate with professional community members (Kozma, Chin, Russell, \& Marx, 2000). Nowadays chemical representations, such as formulas, symbols, equations, and structures, are widely seen in professional journals and routinely used to describe and explain chemical reactions and phenomena. Being familiar with these representations and their usage in chemistry, therefore, is essential for the acquisition of expertise (Kozma \& Russell, 1997; Kozma et al., 2000).

Given the critical role of representations in chemistry, however, the literature indicates that many students have difficulty understanding them. Most students' understanding of chemistry is constrained by the perceptual experiences from their daily lives. They tend to stay at the sensory level and are unable to visualize and interpret molecular and symbolic representations (e.g., BenZvi et al., 1986; Gabel, Samuel, \& Hunn, 1987).

\section{Students' Learning Difficulties}

Three types of students' difficulties in learning chemical representations have been identified. First, a majority of students at the secondary school level cannot appropriately interpret chemical meanings of representations (Krajcik, 1991). Ben-Zvi et al. (1988) explored the levels of description students generated (e.g., the macroscopic level, the atomic molecular level, the multiatomic level) when chemical symbols and formulas were used, such as $\mathrm{Cu}_{(\mathrm{s})}$, $\mathrm{H}_{2} \mathrm{O}_{(\mathrm{l})}$, and $\mathrm{Cl}_{2(\mathrm{~g})}$. Although most of them generated some macroscopic descriptions, such as the physical properties of a compound, the atomic-molecular models they used to explain the phenomena were not appropriate. It seems that students rely on their intuitive mental models of atoms and molecules in their explanations or descriptions about these representations and view chemical formulas as representing one particle without the concept of atoms or a collection. Some students, even after receiving substantial chemistry instruction, still view formulas as abbreviations for names rather than a way to represent the composition or structure, while others hold an alternative conception that a formula is an abbreviation for a mixture (Ben-Zvi et al., 1988).

In addition to the difficulty of interpreting representations, compared with chemists, students are less capable of providing equivalent representations for a given representation (Kozma \& Russell, 1997). According to Keig and Rubba (1993), a large number of students were unable to make translation among formula, electron configuration, and ball-and-stick model and students' performances on translations were correlated to their understanding of underlying concepts. Keig and Rubba argued that making translation between representations is an 
information-processing task that requires understanding of the underlying concept. The conceptual knowledge allows students to interpret the information provided by the initial representation and to infer the details in order to construct the target representation (Lesh, Post, \& Behr, 1987).

A third learning difficulty involves the mental transformation between two-dimensional (2-D) and three-dimensional (3-D) representations. Many students are not able to form 3-D mental images by viewing 2-D chemical structures and to mentally rotate 3-D images (Copolo \& Hounshell, 1995; Seddon \& Eniaiyeju, 1986; Shubbar, 1990; Tuckey, Selvaratnam, \& Bradley, 1991). In order to successfully create a 3-D image by viewing a 2-D diagram, students are required to decode the visual information provided by depth cues used in the diagram (Shubbar, 1990). These depth cues include the foreshortening of lines, relative sizes of different parts of the structure, representations of angles, and the extent to which different parts of the diagram overlap. Tuckey et al. (1991) found that some students cannot correctly identify depth cues, and even if they can, they may not be able to mentally track how depth cues change as a result of rotation (Shubbar, 1990). This makes mentally rotating chemical structures difficult for students.

\section{Linking Visual and Conceptual Information of Chemical Representations}

According to the studies discussed above, when students understand representations, they should be able to generate interpretations, make translations, and mentally manipulate these representations (Kozma \& Russell, 1997). These performances of understanding (Perkins, Crismond, Simmons, \& Unger, 1995) and representational skills require students to have substantial conceptual knowledge and visual-spatial abilities because chemical representations are conceptual constructs as well as visual displays. Due to the exploratory nature of the studies discussed above, however, none of them characterized the process of how students develop chemistry representational skills in a classroom context. Nor did they discuss possible interaction between the visual and conceptual aspects of chemical representations that in our opinion is the core of chemistry visualization. Thus, in this study, we propose a model of visualization by modifying Paivio's dual coding theory (Clark \& Paivio, 1991; Paivio, 1986).

When learning chemical representations, a student may construct three basic cognitive connections involving conceptual and visual information (Fig. 1): (a) representational connections between conceptual information that is presented by an external source and represented by the learner (Connection 1); (b) representational connections between visual information that is presented by an external source and represented by the learner (Connection 2); and (c) referential connections between visual and conceptual systems (Connection 3). In order to demonstrate representational skills, some of the connections need to be activated. For example, translating a chemical formula to a structure might require students to retrieve related conceptual and visual information and activate connections about chemical bonds and the shapes of molecules. This model will be verified by the analysis of students' interactions with the visualization tool, eChem, and their responses to interview questions.

\section{The Use of Molecular Models and Technological Tools}

In order to ease students' difficulties in learning chemical representations, a variety of strategies have been suggested, one of which is an increased use of physical or computational models. Copolo and Hounshell (1995) compared the learning effects of using 2-D, 3-D physical, and 3-D computational models of molecules on student learning of organic chemical structures. Students who used both physical and computational models scored significantly higher on the 


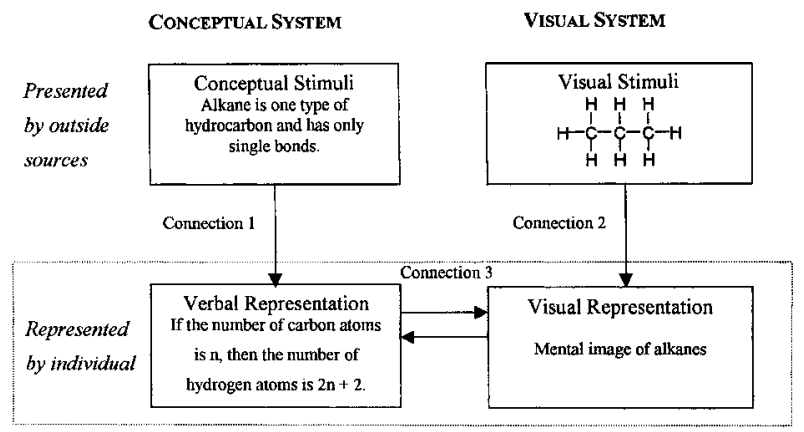

Figure 1. Visual and conceptual systems of dual coding theory—an example of Brian's and Richard's explanations of the general formula of alkanes.

retention test compared to other students who used either 2-D or 3-D models. This suggests that the increased visual stimuli provided by both types of models are more effective. Similarly, Gabel and Sherwood (1980) indicated that manipulating physical models had a long-term cumulative effect on students' understanding. Thus, Copolo and Hounshell concluded that both physical and computational models could offer benefits as an effective instructional tool for teaching molecular structures and isomers. However, this experimental study did not provide qualitative data to examine what features of physical and computational models supported students' learning.

Kozma et al. (1996) indicated that the use of multiple linked representations helped students understand chemical equilibrium and its related chemical concepts. The multimedia environment called MultiMedia and Mental Models (4M:Chem) integrated four chemical systems about equilibrium. It was designed to encourage students to develop expertlike mental models and make connections among symbolic elements, physical features of chemical phenomena, and conceptual entities (Kozma et al., 1996). This study provided insights into how multiple chemical representations and symbol elements interacted with students' mental models. However, 4M:Chem, a well-designed tool, did not give students opportunities to create artifacts or externalize their understanding. All videos, graphs, and animations were already built in, and students could not change or create any representations to meet their learning needs.

With rapid development of Internet technology, more and more molecular modeling tools can be downloaded from the Web, such as the Chime ${ }^{2}$ plug-in, and TINKER-molecular modeling software. Similar to other professional visualizing tools (e.g., CAChe), these programs were designed for college students or chemists. For high school students, as novices in chemistry, these tools are difficult to learn and use. Complicated calculations and parameters, including bond length, bond angle, and vibration energy, are intimidating and overwhelming. In addition, students have to memorize programming languages or commands to use some of these programs. Therefore, a need exists for the development of a simplified version of a visualization tool that includes features similar to professional tools but is easy to use.

In addition, although most empirical studies have shown positive results from using models for chemistry learning at the high school and college levels, the learning issues of how to use models in the classroom context should not be oversimplified. As O'Connor (1997) has suggested, teachers "must give much attention to the selection, use, integration, and limitations of models" (p. iv). Despite extensive exposure to models in lectures, textbooks, and computerbased activities, the college students in her study still used surface features of models to 
construct their explanations and overlooked the relevant concepts underlying models. Thus, this study addresses the issue of how students use molecular models to learn chemical representations and explores what aspects or features of a technological tool support them in doing so.

\section{Description of eChem}

Students in this study used eChem, a simplified and learner-centered version of professional visualizing tools developed by the Center for Highly Interactive Computing in Education (hi-ce) at the University of Michigan. Learner-centered design (LCD) addresses the unique needs of learners. The design principles support acquisition and growth of expertise, address diversity of learners' backgrounds, and promote and sustain motivation (Jackson, Krajcik, \& Soloway, 1998; Soloway, Guzdial, \& Hay, 1994; Soloway et al., 1996).

eChem guides students in three main actions-building molecular models, visualizing multiple 3-D models, ${ }^{3}$ and comparing micro and macroscopic representations. It provides three tasks: Construct, Visualize, and Analyze. In Construct students can create organic molecular models, view them from all possible angles, and manipulate them more easily than physical balland-stick models (see Fig. 2). Visualize provides students with multiple views of different compounds and various representations such as ball-and-stick, wire-frame, and space-filling simultaneously (see Fig. 3). In Analyze students can make connections between molecular models at the microscopic level (e.g., molecular structures) and their collective behaviors at the macroscopic level (e.g., chemical and physical properties).

eChem integrates various supports for chemistry learning (Table 1). To support the acquisition of expertise for high school learners, eChem simplifies the periodic table to an atom palette (Fig. 2). Rather than providing the full scope of chemical bonding, constraining the scope to covalent compounds simplifies the learning process, lowers the cognitive burden, and reduces

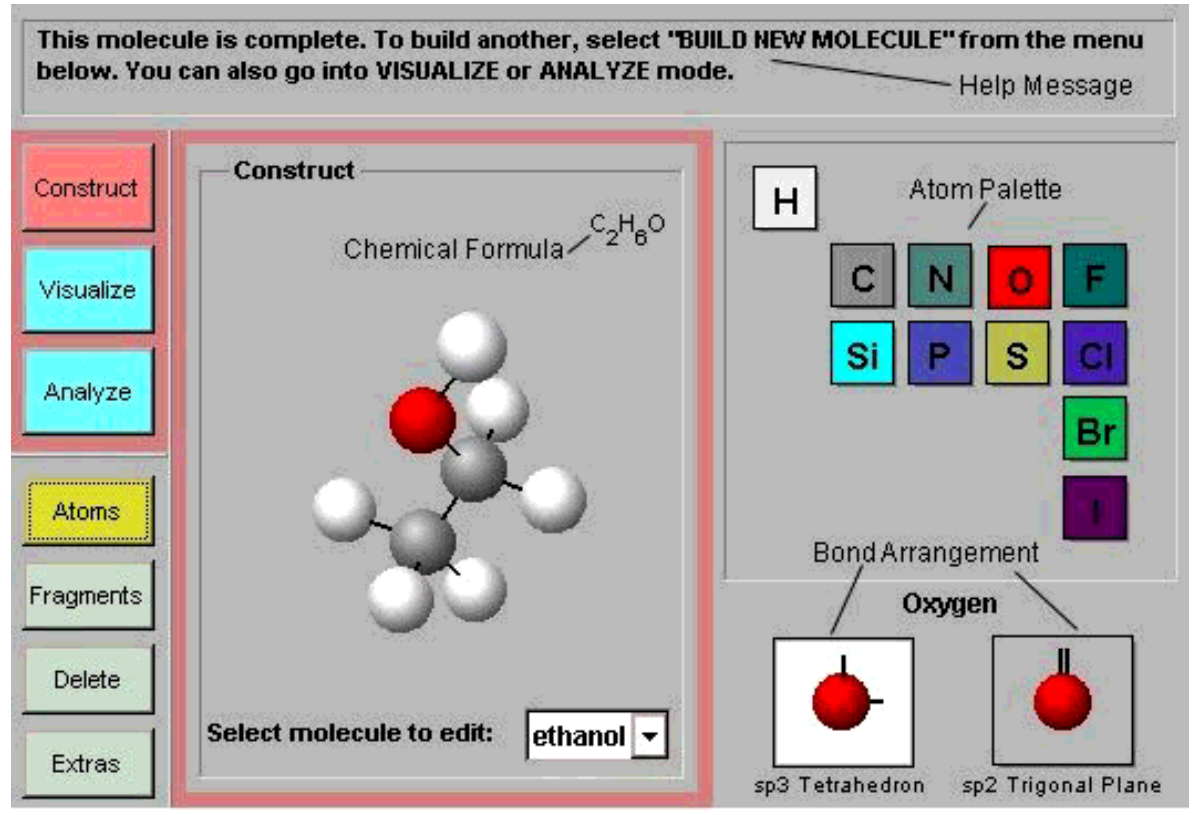

Figure 2. The graphic interface of the Construct page. 


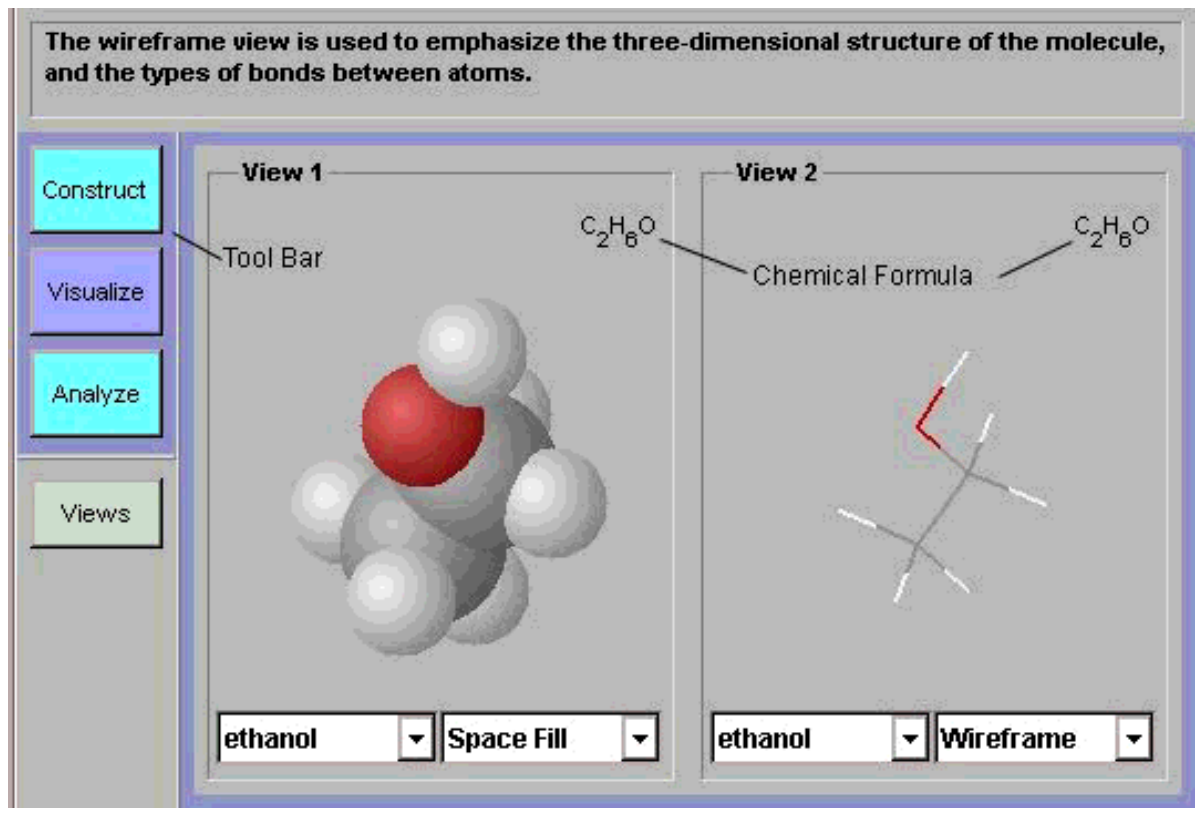

Figure 3. The graphic interface of the Analyze page.

the complexity of creating computerized models for novice users. Furthermore, eChem provides only possible bonding arrangements (hybridization; see Fig. 2) to support learners in creating appropriate chemical models. Although the number of bonding arrangements is limited, complicated molecular models are still doable with eChem. For example, with a growth in expertise, students can use eChem to construct complex molecules such as glucose, DDT (dichlorodiphenyl trichloroethane), and fatty acids. In addition, when students choose and switch between different actions, the help messages support their learning and using processes.

To address the diversity of learners' backgrounds and to facilitate visual engagement, eChem's visual interface supports a nonlinear path to construct, visualize, and analyze molecular models. Students can switch between actions and features easily by clicking buttons on the tool bar. Its multiple representations allow students with different learning styles to choose their preferred symbol systems (Salomon, 1979) and encourage them to make connections between verbal and visual representations simultaneously (Clark \& Paivio, 1991; Paivio, 1986). Moreover, colorful graphic interfaces enhance students' visual engagement. Compared with built-in multimedia software, which has a limited number of molecules to manipulate, eChem allows students to revise their models and create their own database of compounds over time.

\section{Methods}

\section{Participants}

This study was conducted at a small public high school in a midsize university town in the Midwest. The teachers in the science program worked with educational researchers from a local 
Table 1

Learning supports provided by eChem on the three tasks

\begin{tabular}{|c|c|c|c|}
\hline Learning Supports & Construct & Visualize & Analyze \\
\hline \multicolumn{4}{|l|}{ Growth of Expertise } \\
\hline \multirow{3}{*}{$\begin{array}{l}\text { Multiple linked } \\
\text { representations }\end{array}$} & Chemical name $(\mathrm{S})$. & Chemical name $(\mathrm{S})$. & Chemical name $(\mathrm{S})$. \\
\hline & Formula $(\mathrm{S})$ & Formula (S). & Ball-and-stick model (MI). \\
\hline & $\begin{array}{l}\text { Ball-and-stick } \\
\text { models (MI). }\end{array}$ & Various 3D models (MI). & Property (MA). \\
\hline \multirow[t]{5}{*}{ Reduce complexity } & $\begin{array}{l}\text { Simplified periodic } \\
\text { table. }\end{array}$ & Select molecules. & Select molecules. \\
\hline & Bond arrangements. & Select models. & Spread sheet of structures \\
\hline & Model rotation. & Model rotaion. & and properties. \\
\hline & Fragments & & Model rotaion. \\
\hline & Extras. & & \\
\hline Explicit guidance & Help message. & Help message. & Help message. \\
\hline \multicolumn{4}{|l|}{ Diversity of learners } \\
\hline \multirow{3}{*}{$\begin{array}{l}\text { Multiple } \\
\text { representations }\end{array}$} & Chemical name $(\mathrm{S})$. & Chemical name $(\mathrm{S})$. & Chemical name $(\mathrm{S})$. \\
\hline & Chemical formula $(\mathrm{S})$. & Chemical formula $(\mathrm{S})$ & Ball-and-stick model (MI). \\
\hline & $\begin{array}{l}\text { Ball-and-stick } \\
\text { model (MI). }\end{array}$ & $\begin{array}{l}\text { Multiple } 3 \mathrm{D} \\
\text { representations (MI). }\end{array}$ & Property (MA). \\
\hline \multirow[t]{2}{*}{ Nonelinear path } & Tool bar. & Tool bar. & Tool bar. \\
\hline & Graphic interface. & Graphic interface. & Graphic interface. \\
\hline \multicolumn{4}{|l|}{ Motivation } \\
\hline \multirow{2}{*}{$\begin{array}{l}\text { Visual engagement } \\
\text { Sustain } \\
\text { engagement }\end{array}$} & Graphic interface. & Graphic interface. & Graphic interface. \\
\hline & $\begin{array}{l}\text { Revised models. } \\
\text { Molecule database. }\end{array}$ & & Property database. \\
\hline
\end{tabular}

Note. $\mathrm{MA}=$ macroscopic representation; $\mathrm{MI}=$ microscopic representation; $\mathrm{S}=$ symbolic representation.

university to develop and implement a three-year inquiry-based science curriculum (HeubelDrake, Finkel, Stern, \& Mouradian, 1995). Seventy-one 11th graders participated in this study (35 females and 36 males), and they were taught by three teachers. Because most students had previous experiences with the instructional approach in their freshman and sophomore years, they were familiar with the features of this curriculum, including an emphasis on asking questions, long-term investigation, collaboration, and the use of technological tools. The students in this study had a range of ethnic backgrounds, academic abilities, and socioeconomic levels, although the majority were middle- to upper middle-class Caucasians. In each class three dyads (a total of six students) were nominated as the target students from consideration of their genders, ethnic backgrounds, learning achievement in the past two years, and ability to verbalize their learning process. Among these 18 target students, eight were female and two were African American.

Three teachers, Marcia, Karen, and Mark, ${ }^{4}$ each taught one section and had more than five years of science teaching experiences. Marcia has a background in biology, while Mark and Karen majored in chemistry. They met twice a week for planning curriculum, creating materials, sharing handouts, and discussing students' progress.

\section{eChem Learning Activities}

The use of the tool eChem was integrated into a 6-week unit-the Toxin Project. In this unit teachers provided a list of known toxins. Students worked with one or two classmates and 
selected a known toxin to investigate. The driving question (Marx, Blumenfeld, Krajcik, \& Soloway, 1997) of this project was: "Is my drinking water safe?" To answer this question, students listened to lectures on relevant chemical concepts, searched for information from the web, watched videos of water-treatment and environmental science, carried out lab activities of solubility and water purification, built physical and eChem models, and designed Web pages for final products. Chemical concepts covered by this 6-week project were VSEPR (valenceshell electron pair repulsion) theory, covalent bonds, polarity of bonds, IUPAC (International Union of Pure and Applied Chemistry) nomenclature of organic compounds, and molecular structures.

From Week 2 to Week 4 students had learning activities that incorporated the main actions of eChem for studying hydrocarbons and alkanes (eChem I), names of alkanes (eChem II), and representations of chemistry (eChem III). The first eChem activity was tied to a lecture on covalent bonds and introduced structures and properties of organic compounds. Students constructed models of alkanes, viewed various representations simultaneously, and developed an understanding of the relationship between boiling points of alkanes and their number of carbon atoms. The second activity introduced the IUPAC (International Union of Prue and Applied Chemistry) nomenclature of organic compounds, the naming rules currently used in chemistry. Students created models on eChem and followed the rules to name their models. For example, they made an eChem model with a total of six carbon atoms and one substituent group and then named and drew it on paper. The third activity was designed for students to visualize various two-dimensional (2-D) and three-dimensional (3-D) chemical representations. The 2-D representations included structural formulas, condensed structural formulas, very condensed structural formulas, and chemical formulas. The 3-D models constructed in this activity were ball-and-stick, space-filling, and wire-frame models. Students constructed models on eChem and with ball-and-stick model kits and compared differences and similarities between these two types of models. For example, because the single bonds created on eChem cannot be twisted, students built isomers on eChem and by physical model kits, predicted whether or not they were the same compounds, and manipulated models to support their predictions.

Although the main eChem activities were finished within 3 weeks, the eChem was used throughout the entire unit. During class discussions the teachers frequently referred to eChem activities when they introduced the concepts of molecules, covalent bonds, and structures. They also had students compare differences among 2-D structural formulas, physical models, and eChem models. Moreover, students used eChem to construct 3-D models of their toxins, posted these models on their Web pages, and used 3-D structures to justify their arguments about polarity, solubility, and toxicity.

\section{Data Collection}

Multiple sources of data were collected over the 6-week period including: curriculum materials, classroom video recordings, field notes, pre- and posttests, video recordings of students using eChem, artifacts, and interview transcripts. Curriculum materials, classroom videos, and field notes of classroom observations were collected to describe the implementation of the curriculum. All participants $(N=71,35$ females $)$ took pre- and posttests. Twenty-one items were grouped into three types of conceptual understanding: (a) chemical representations, (b) chemical concepts underlying representations, and (c) connections between properties and molecular structures (Table 2). Students were asked to make 2-D and 3-D translations, compare structural differences based on 2-D structural formulas, identify types of bonding based on chemical formulas, and determine the polarity of molecules by structures. 
In addition, video recordings of students using eChem (process videos), students' artifacts, and interview data were collected from 18 target students (three dyads in each of three classes). Process videos captured the activities on a computer screen and the conversations of target groups (Krajcik, Simmons, \& Lunetta, 1988). Students' artifacts included worksheets of eChem activities, models built by eChem, and Web pages designed for final products.

During interviews target students were asked to represent an organic compound in various ways, manipulate molecular models mentally, and make translations between various representations. For example, students were showed a chemical formula, $\mathrm{C}_{5} \mathrm{H}_{10}$, and asked to draw its 2-D structure and represent it in different ways. They were also shown different types of 3-D models (i.e., ball-and-stick, wire-frame, and space-filling models) on a computer screen and asked to indicate whether the models represented the same chemical molecule. Eighteen target students were interviewed as pairs. Each interview lasted about $30 \mathrm{~min}$ and was conducted outside the science classroom. Several interview strategies were used. First, any information about chemical bonds and related concepts were not mentioned unless the topic was raised by students. Second, any unclear student responses were questioned further. Third, the interviewer remained open to emerging meanings and alternative explanations for the interview questions, although this study was not designed to explore students' alternative conceptions of chemical representations.

\section{Data Analysis}

Process videos. Process video data were viewed and coded utilizing a software program called Event Recorder (Berger, Walton, Jones, \& Wurman, 1995). It allowed us to code, analyze, and display data from observations by recording a sequence of events in real time. These videotapes were coded by an analysis scheme that included students' actions of using eChem (e.g., constructing models, using the visualizing feature, and analyzing properties), their actions with the use of eChem (e.g., reading aloud, writing worksheets, making comments, and discussing), and their interactions with teachers and the researcher (e.g., interventions). The

Table 2

Categories of conceptual understanding and items of Pre- and Posttests

\begin{tabular}{lll}
\hline Conceptual Understandings & & \multicolumn{1}{c}{ Items } \\
\hline Chemical representation & Chemical formula & $2^{* *}, 8^{* *}, 12^{* *}$ \\
& Structural formual & $9^{* *}, 17^{* *}$ \\
& Electro dot structure & $7,14^{* *}$ \\
& 2D-3D translation & $12^{* *}, 14^{* *}$ \\
& Chemical formula-structure translation & $9^{* *}$ \\
& Compare structural difference & $18,19^{* *}, 20^{* *}, 21$ \\
Chemical concepts underlying & Electron configuration & 1,7 \\
representations & Covalent and ionic bonds & $2^{* *}, 3^{* *}, 7$ \\
& VSEPR theory & $5^{* *}$ \\
& Organic compounds & $3^{* *}$ \\
Properties and molecular structure & IUPAC nomenclature & $10^{* *}, 13^{* *}$ \\
& Polarity & $4^{* *}, 6^{* *}, 15^{* *}, 16^{* *}$ \\
& Boiling point & $11^{* *}$ \\
& Solubility & $15^{* *}, 16^{* *}$ \\
\hline
\end{tabular}

Note. **means that two-tailed $t$-test shows significant difference between pre- and posttest $(p<.01)$ in the item. 
amount of time students stayed in each action of eChem and the frequency students used specific features showed how various features in eChem, such as model rotation and chemical formula, helped students construct models and make translations between representations. We also examined students' levels of engagement. We define engagement as the amount of time students spent on discussions while using eChem. High engagement means that a student dyad spent a relatively greater amount of time on thoughtful discussions containing back-and-forth dialogues. All thoughtful discussions were transcribed, that provided rich information for the investigation of how students developed an understanding of molecular models.

Interview transcripts. The interviews of target students were transcribed, coded, and analyzed to assess target students' understanding of representations. Three types of representation competence are: (a) understanding related to properties and structures, (b) understanding of underlying concepts, and (c) ability to translate various representations. Each type was categorized into three levels (Table 3). According to students' responses, their conceptual understanding was coded as accurate, partial, and none, and their ability of translation was coded as high, adequate, and low.

Artifacts. The artifacts included worksheets of eChem activities, models built by eChem, and Web pages designed for the final products. They demonstrated students' learning progress over time. They were used to triangulate the findings of process videos and interview transcripts. For example, models and information presented on Web pages were examined as to whether they were coherent with students' responses to interview questions and whether students had preferences for using a particular type of model.

Curriculum materials, classroom videos, and field notes of classroom observation. Curriculum materials, classroom videos, and field notes of classroom observation were collected to describe the implementation of the curriculum. These data were not coded and analyzed in detail; rather, they were used to display the major events of the day and particular episodes related to learning chemical representations and the use of eChem. The data from these three resources offered evidence for examining assertions generated from other data resources. For example, students' interpretations of chemical representations in interviews may be shaped by explanations that teachers provided in the class. In addition, because the process videos did not record students' physical activities and facial expressions, the data from classroom video recordings were used to complement and triangulate the findings of process video analysis.

\section{Data Synthesis}

To answer the research questions, we combined the data of process videos, artifacts, and interviews. The analysis scheme included a detailed description of each process video and interview, i.e., what students did and what they discussed when using eChem. Cases were created for each pair of focus students, and cross-cases analyses were used for determining the commonalties, differences, and difficulties of translation and model construction. To draw conclusions, the data analysis involved generating assertions by searching for the data corpus, establishing an evidentiary warrant for the assertions, and verifying assertions by confirming and disconfirming evidence (Erickson, 1986).

\section{Findings and Discussions}

This section consists of four parts and follows the research questions. To answer our question of whether students are able to make translations among representations after using 
Table 3

Categories and levels for coding interview transcripts

\begin{tabular}{|c|c|c|c|c|}
\hline Level & $\begin{array}{l}\text { Understanding } \\
\text { Related to Properties } \\
\text { and Structures }\end{array}$ & $\begin{array}{l}\text { Understanding } \\
\text { of Underlying } \\
\text { Concepts }\end{array}$ & Level & $\begin{array}{c}\text { Ability to Translate } \\
\text { Various } \\
\text { Representations }\end{array}$ \\
\hline Accurate & $\begin{array}{l}\text { Students are able to: } \\
\text { Predict a chemical } \\
\text { compound's polarity } \\
\text { and solubility based } \\
\text { on its structure } \\
\text { correctly. } \\
\text { Provide accurate } \\
\text { explanations for their } \\
\text { predictions on polarity } \\
\text { and solubility in } \\
\text { chemistry terms. } \\
\\
\text { Provide an appropriate } \\
\text { molecular structure } \\
\text { base on it polarity } \\
\text { and solubility. }\end{array}$ & $\begin{array}{l}\text { Students are able to: } \\
\text { Represent an organic } \\
\text { molecule in various } \\
\text { ways, and describe } \\
\text { visual differences } \\
\text { between these } \\
\text { representations based } \\
\text { on the underlying } \\
\text { concepts such as } \\
\text { bonding theory. } \\
\text { Identify isomers by } \\
\text { viewing two- } \\
\text { dimensional models. } \\
\text { Apply underlying concepts } \\
\text { to justify their predictions } \\
\text { or explanations about } \\
\text { representations. } \\
\text { Manipulate molecular } \\
\text { models mentally. }\end{array}$ & High & $\begin{array}{l}\text { Students are able to: } \\
\text { Make translation } \\
\text { between chemical } \\
\text { formula and } \\
\text { structural formula. } \\
\text { Make translation } \\
\text { between structural } \\
\text { formula and 3D } \\
\text { models. } \\
\text { Make translation } \\
\text { between three types } \\
\text { of 3D models. } \\
\text { Identify functional } \\
\text { groups by viewing } \\
\text { 2D or 3D models. }\end{array}$ \\
\hline Partial & $\begin{array}{l}\text { Students are able to } \\
\text { demonstrate some of } \\
\text { the three performances } \\
\text { presented above. }\end{array}$ & $\begin{array}{l}\text { Students are able to } \\
\text { demonstrate some of } \\
\text { the four performances } \\
\text { presented above. }\end{array}$ & Adequate & $\begin{array}{l}\text { Students are able } \\
\text { to demonstrate } \\
\text { two or three } \\
\text { performances } \\
\text { presented above. }\end{array}$ \\
\hline Non & $\begin{array}{l}\text { Students are not able to } \\
\text { demonstrate any } \\
\text { of the three perfor- } \\
\text { mances presented } \\
\text { above. }\end{array}$ & $\begin{array}{l}\text { Students are not able to } \\
\text { demonstrate any of } \\
\text { the four performances } \\
\text { presented above. }\end{array}$ & Low & $\begin{array}{l}\text { Students are able to } \\
\text { demonstrate one } \\
\text { or none of the } \\
\text { performances } \\
\text { presented above. }\end{array}$ \\
\hline
\end{tabular}

eChem, the first part presents statistical results regarding students' conceptual understanding and translation skills before and after using eChem. We then describe the findings of the qualitative data analysis, which indicate possible explanations of students' learning patterns and illustrate the process of how students made translations among representations. Finally, we indicate how features on eChem might promote students' learning of representations.

\section{Students' Abilities to Make Translations Among Chemical Representations}

The results of pretest $(N=71, M=31.1)$ and posttest $(N=71, M=59.5)$ indicate that students' understanding of chemical representations improved substantially. A paired twosample $t$ test for means shows a statistically significant difference between the means of pre- and 
posttests $[t(70)=13.9, p<.001]$. Moreover, the effect size indicates that the average score on the posttest was more than 2.5 standard deviations greater than the average score on the pretest (effect size $=2.68$ ). Although it is impossible to separate the learning effects by instructions and by use of a technological tool, these results show that after this 6-week project, the majority of students acquired conceptual knowledge at the macro- and microscopic levels and were able to translate various chemical representations.

The statistical comparison of the results of students' performance on test items are shown in Table 2. Each item is categorized as one of the three types of conceptual understanding. Regarding our first research question, as shown in Table 2, students performed significantly better on Items 9, 12, and 14 on the posttest. These items in particular required students to translate a 3-D model to a chemical formula and an electron dot structure. These translations were solely introduced and practiced during eChem learning activities. This may indicate that manipulating eChem models and doing eChem-related activities facilitated the development of translation abilities. As we will discuss later, features in eChem, such as model rotation and bond arrangements, assisted students in visually connecting 2-D and 3-D models, which may contribute to the improvement of their translation ability.

\section{Learning Patterns While Translating Representations and Constructing eChem Models}

In the following we present the learning patterns students demonstrated while using eChem. To describe in what ways eChem enhanced students' translation skills, we also compare the use of eChem with physical models.

Engagement and the nature of discussions while using eChem. As mentioned previously, engagement is defined by the amount of time students spent on thoughtful discussions while using eChem. The analysis of interview transcripts shows that highly engaged students demonstrated a more accurate conceptual understanding of properties, structures, and underlying concepts.

Analysis of the process videos (i.e. video recordings of students using eChem) provides possible explanations of how students' engagement may contribute to their conceptual understanding. While some target students simply followed the instructions step by step without discussing how and why atoms had different ways of bonding, highly engaged students' discussions involved the underlying concepts of the representations through which students developed a deeper understanding of chemical representations. The following segment is one of the examples. This segment illustrates how Maggie and Steve determined which bond arrangement was appropriate for a propane model while using eChem. This was their first day using eChem. They had limited prior knowledge of chemical bonds and hydrocarbons at that time, although they had knew that carbon atoms normally have four bonds. Prior to creating a propane model, they had experience in trying to build methane and ethane models on eChem, but none of them was chemically correct. The worksheet provided the chemical formulas of methane and ethane, and students were asked to predict the chemical formula of propane and to search for a pattern for the number of hydrogen atoms in alkanes.

Steve: One is gonna be like this. [His figure pointing to one of the bond arrangements: sp linear, a carbon atom with two double bonds.]

Maggie: No, wait, wait. It could be four [sp3 tetrahedron], right?

Steve: Let's try this way. [Selects the carbon atom with two double bonds and clicks it on the canvas as the first carbon atom.] Right? 
Maggie: Well, it could look either way. It could be $\mathrm{C}_{3}, \mathrm{H}$...[Looking at the eChem worksheet and searching for the number of hydrogen atoms.]

Steve: ...Three carbons, eight hydrogens. [Looking at the sheet, too.]

Steve: The carbon could be...we got this [ $\mathrm{sp}^{3}$ tetrahedron]. We got this $\left[\mathrm{sp}^{2}\right.$ trigonal plane].

[Maggie points to $\mathrm{sp}^{2}$ trigonal plane. Steve then selects two carbon atoms with $\mathrm{sp}^{2}$ hybridization and attaches them on the first carbon they had chosen. They create a diene model on the screen.]

Maggie: See, we can also choose this carbon $\left[\mathrm{sp}^{3}\right]$ and put it in the middle. Then we got two more hydrogens.

Steve: Is that right? [Attaches four hydrogen atoms on the diene model.]

Maggie: I don't know. [Turns to the teacher, Mark, and asks for help.]

Maggie: Mark, there are two ways to do this.

Mark: Ah...that's the joy of chemistry.

From the class instruction Steve and Maggie acknowledged that hydrocarbon compounds were composed of carbon and hydrogen atoms. However, they did not realize how complicated chemical bonding of a hydrocarbon compound could be until they had an opportunity to construct a propane model. Bond arrangements of carbon provided by eChem encouraged them to consider that different bond arrangements determine the number of hydrogen atoms attaching on a carbon atom, even though the total number of bonds a carbon atom has is the same. To accomplish the task, Maggie and Steve had to apply their conceptual knowledge of bonding and hydrocarbons. This segment illustrates that highly engaged students' discussions involved the conceptual aspect of representations, such as bonding and the definition of alkanes. The bond arrangement feature on eChem potentially promotes student to explore various types of chemical bonding, to search for patterns, and to make chemistry bonding meaningful.

Rotation feature and transformation between 2-D and 3-D models. Another learning pattern was demonstrated by target students regardless of the degree of engagement. When using eChem, seven among the nine student pairs consciously rotated 3-D models to make the depth cues disappear. During the 6-week unit structural formulas and other 2-D representations were introduced to students before they used eChem. Students became familiar with the symbol system (Salmon, 1979) of hand drawings or printed 2-D structures [Fig. 4 (a)]. The first challenge for students in making sense of the 3-D views of molecules was to decode the information on bond angles and the geometry of molecules that was not represented in 2-D structures. Analysis of process videos shows that a majority of target students consciously rotated a 3-D propane model [from Fig. 4 (b) to Fig. 4 (c)] because through this rotation process, a 3-D model shared similar visual features of the 2-D one, such as the relative location of hydrogen and carbon atoms and a linear carbon chain. By externalizing the transformation process between 2-D and 3-D models, the rotation feature provided by eChem may contribute to students' better performances on test items that required substantial 2-D and 3-D transformation skills (Table 2).

Students' perceptions of eChem and 3-D models. During final interviews, in response to structural differences between two structural formulas, the majority of students formed and manipulated a model mentally. As students described them, their mental images were built on 
either physical or computational models shown or used in class activities. For example, in response to an interview question, identifying whether two structural formulas were representing the same molecule, Steve said,

Those are different [Fig. 5]. Now I'm picturing the examples like Mark [the teacher] did with the little models [physical models] with the springs. You can't turn it like here the chlorine and $\mathrm{CH}_{3}$. They are on the opposite sides, you know. Here [Fig. 5(b)] is on the same side. You can't just turn it because the double bond doesn't work that way; you can't just twist it.

Another student, Jerry, thought both eChem and physical models helped him visualize 3-D models. When asked about which models he manipulated mentally to answer questions in terms of 3-D models, Jerry said,

Both actually. I like eChem. You know, you are able to rotate them. This thing [physical model] of course, you know, it's in you hands, when eChem is only on the computer.

These two segments illustrate that both physical and computational models can be vehicles of students' mental images, although these two types of models convey information by two different symbol systems (Salomon, 1979). In addition, students noticed the limitations and advantages of these two types of models. Although manipulating physical models provided concrete feelings of models, eChem models were easily rotated, created, and modified.

Among three types of 3-D models provided by eChem (i.e. ball-and-stick, wire-frame, and space-filling models), the analysis of artifacts and interviews shows that students had preferences in using a specific type of model to illustrate ideas. Instead of using wire-frame models, all target dyads used ball-and-stick models to represent their toxins on final products. During final<smiles>CCC</smiles>

(a)

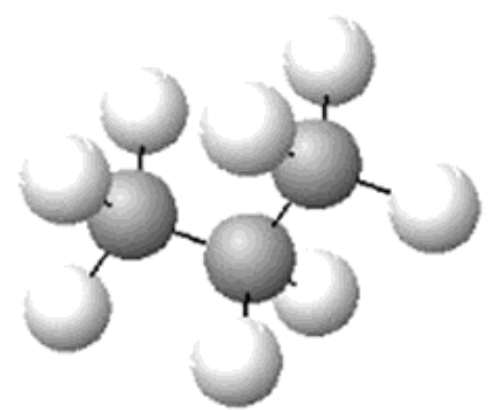

(b)

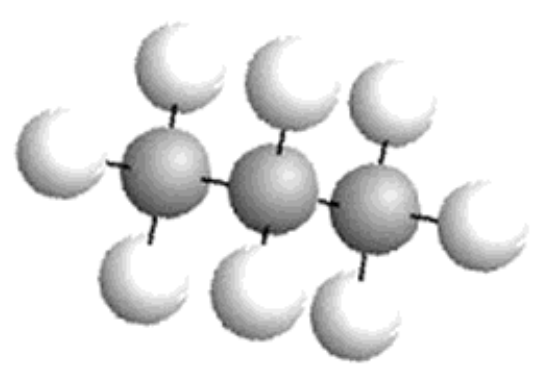

(c)

Figure 4. $2 \mathrm{D}$ and $3 \mathrm{D}$ representations of propane $\left(\mathrm{C}_{3} \mathrm{H}_{8}\right)$. 
<smiles>CC=CCl</smiles>

(a)

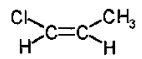

(b)

Figure 5. Trans- and cis-isomers.

interviews, when asked to identify functional groups, compare structural differences, or make translations by viewing different types of 3-D models, students spent less time relatively in coming up with answers if they were allowed to see the ball-and-stick models. Although the process videos showed that space-filling models were the most visually attractive to students, students did not prefer using them in identifying structural differences and functional groups because bond orders were invisible in this type of model. Therefore, among the three types of 3D models, wire-frame models may be too abstract in showing only carbon chains. Space-filling models do not demonstrate bond orders directly. The ball-and-stick models were the most concrete ones for students because they convey the visible information of atoms and bond orders.

\section{Linking Visual and Conceptual Information of Representations}

The analysis of interview transcripts allows us to characterize the process of how the students made translations among representations. During interviews nine target student pairs were asked to translate a chemical formula, $\mathrm{C}_{5} \mathrm{H}_{10}$, into a structural formula. Five pairs successfully completed the translation, and their answer was either cyclopentane or pentene. The analysis of interview transcripts suggests that the approach students took to solve the problem determined their answer. Two student pairs whose answer was pentene tended to first compare $\mathrm{C}_{5} \mathrm{H}_{10}$ to $\mathrm{C}_{5} \mathrm{H}_{12}$ (pentane) and then realized that $\mathrm{C}_{5} \mathrm{H}_{10}$ has two hydrogen atoms fewer. Fewer hydrogen atoms indicate the existence of a double bond, so $\mathrm{C}_{5} \mathrm{H}_{10}$ could be pentene. Similar to the first step that the "pentene" group took, students whose answer was cyclopentane first compared $\mathrm{C}_{5} \mathrm{H}_{10}$ to $\mathrm{C}_{5} \mathrm{H}_{12}$. Yet this comparison led them to come up with an idea that the structure must look like a circle. The following segment is an example of how students translated $\mathrm{C}_{5} \mathrm{H}_{10}$ into cyclopentane:

[The interviewer shows them a chemical formula, $\mathrm{C}_{5} \mathrm{H}_{10}$, and asks the students translate it to a structural formula.]

Brian: Is it cyclopentane? [Looking at Richard.]

Richard: What?

Brian: It's like a circle [using fingers to make a circle]. It's not pentane because it's C-5, H-12.

Interviewer: How do you know that?

Richard: Because the formula for it, is it $2 n+2$ ?

Brian: If you get carbons, two hydrogens attach each carbon, except the ends [using one hand to show a linear carbon chain and moving the other hand to locate where hydrogen atoms are around this chain].

Brian: I am thinking cyclopentane because there aren’t extra two.

The process videos showed that during eChem activities, Brian and Richard generated the general formula of alkanes by based on a series of alkane models they built on eChem. The 
segment above indicates they developed a conceptual linkage between formulas and structures, which included the information of symbols, structures, and mental images. As they compared the unfamiliar formula, $\mathrm{C}_{5} \mathrm{H}_{10}$, to their mental model of noncyclic alkanes, they compared the conceptual information provided by formulas, that is, the number of hydrogen atoms, as well as the visual information provided by structures, that is, a chain and a circle. Brian's and Richard's explanations reveal the interweaving nature of visual and conceptual understandings in chemistry. To further illustrate this translation process, we use Paivio's dual coding theory (Paivio, 1986) to indicate the possible interactions between visual and conceptual systems (Fig. 1).

During eChem activities Brian and Richard constructed a conceptual connection between the chemical definition of alkanes and the general formula (Connection 1), a visual connection between structural formulas and correspondent mental models (Connection 2), and referential connections between this general formula and their mental models (Connection 3). When they answered the question of translating $\mathrm{C}_{5} \mathrm{H}_{10}$ to a structural formula, all these connections were activated. Examples of Connection 1 are the following comments by Brian and Richard respectively: "It's not pentane because it's C-5, H-12" and "Because the formula for it, is it $2 n+2$ ?" Brian externalized Connection 2 through his body language and spoke out that "if you get carbons, two hydrogens attach each carbon, except the ends." As Mayer and Anderson (1992) indicated, problem-solving transfers require both representational and referential connections. To determine whether $\mathrm{C}_{5} \mathrm{H}_{10}$ could be cyclopentane, Brian had to activate the referential link to identify whether $\mathrm{C}_{5} \mathrm{H}_{10}$ followed the general formula and then triggered other possible links to solve this problem. Therefore, making translations between chemical representations could involve not only retrieving conceptual knowledge of chemical representations but also creating mental images of them.

\section{Feature Analysis}

As discussed previously, the rotation feature in eChem helped students visualize how to transform a 2-D model into a 3-D model. This feature also assisted students in constructing models. Process videos showed the majority of students frequently used model rotation to make empty bonding sites visible. The chemical formula displayed on the Construct page assisted students in identifying empty bonding sites and translating a structural formula into a 3-D model, as they frequently compared the chemical formulas in eChem to the ones they intended to build. After using eChem for 1 week, some target students explored features that were not mentioned in the worksheets. For instance, they frequently used "Extras" and "Fragment" as shortcuts for model construction. The Extras feature allowed them to fill out all hydrogen atoms by one click, and Fragment provided long carbon chains and a benzene ring. These two features were both designed to simplify the complexity of model construction. However, when encountering utility problems, none of the students read the help message-a feature designed to scaffold the learning process.

\section{Conclusions}

\section{Students' Translation Skills and Computational Models}

Recent research has suggested that using computational and physical models can promote chemistry learning (e.g., Copolo \& Hounshell, 1995). This study provides both qualitative and 
quantitative data to examine the learning effects of using computerized models. A positive learning effect, shown by the significant difference between the scores of pre- and posttests, may be partially attributed to using a visualization tool in science classrooms. A computer-based visualization tool like eChem in particular improved students' ability to make transformations between 2-D and 3-D models, and this ability might help them to develop an understanding of isomers and polarity. Although eChem assisted students in developing an understanding of chemical representations, this study does not conclude that either the computational model or the concrete model is the best for chemistry learning. Instead, through analyses of interviews and process videos, this study suggests that both types of models should be provided through class instruction because different students have preferences for different types of models and symbol systems.

\section{Students' Preferences of Molecular Models}

In Harrison and Treagust's study (1996) of students' mental models of atoms and molecules, students had a strong tendency to select the space-filling molecular model as a better representation of a molecule. Similar to their findings, in our study two target students, Brian and Richard, used both ball-and-stick and space-filling models to represent their toxin on their Web page and viewed the latter model as "a more realistic depiction" However, without showing bond orders, the space-filling model was not the most visualizable model for students to identify functional groups and make translations during interviews. Although the ball-and-stick models do not demonstrate either appropriate atom sizes or electron clouds surrounding atoms, using them to offer a concrete experience of chemical bonds, atoms, and molecules is necessary for high school students. After students develop a basic understanding of bonding, teachers could provide various 3-D models and guide group discussions of how different models convey different information about bonding, atom size, and electrons, as Harrison and Treagust (2000) suggested in their case study. Through discussing or negotiating meanings within a class or within groups, students would be able to realize the limitations and benefits of using different types of representations and to learn to appropriately use different models to solve problems, just as chemists do (Kozma \& Russell, 1997).

\section{Encouraging the Development of Visual and Conceptual Connections}

Students could develop referential connections between visual and conceptual systems that help them make translations among representations. Conceptual knowledge as well as mental images could be cognitive resources for students to demonstrate representational skills. As shown by Brian and Richard, even though some students did not have conceptual understanding of alkenes, they could still successfully accomplish the translation task by manipulating a mental image of alkane.

To encourage the development of visual, conceptual, and referential connections, providing multiple linked representations should be a design principle for chemistry visualization tool (Kozma et al., 1996). This linked feature is as important as providing multiple representations. When visual representations are accompanied by text, students may not be able to make referential connections among them, or even if they do, they may create incorrect connections. Thus, after the multiple representations and descriptions are provided, learning tools need to facilitate an additional comprehension stage - to resolve coreferences between the two representations (Narayanan \& Hegarty, 1998). If this stage is not successful, students tend to construct a connection between representations based on surface features, such as colors 
and types of symbol systems, rather than underlying concepts (Kozma \& Russell, 1997). On eChem the chemical formula changed when students attached more hydrogen atoms to a carbon chain. This linked representation feature would allow students to build a conceptual connection as well as visualize how to transform one representation into another. This in turn may enhance students' representational skills, such as making translations among representations.

\section{Visualization Tools and Chemistry Learning}

This study has revealed how students use eChem to assign meanings to novel representations. Two eChem features are crucial for these processes. First, although the bond arrangement feature limits students' capability of constructing unstable compounds (e.g., CO and ozone), it encourages students to apply chemical concepts they have learned to be able to choose appropriate bonding. As in Kozma (2000), students' discourses and social interactions were influenced by the resources available to them. Using a visualization tool that illustrates symbolic and microscopic representations encourages students to engage in a discussion of underlying concepts. The action of selecting bond arrangement strengthens and builds students' conceptual linkages among bonding, structures, and molecules. Second, the model rotation feature provided by eChem assists students in making visual connections between 2-D and 3-D models. As the empirical studies have shown, a moderate correlation between spatial ability and learning achievement in chemistry (Carter, LaRussa, \& Bodner, 1987; Pribyl \& Bodner, 1987), manipulating computerized models could improve students' spatial abilities (Barnea \& Dori, 1999). Through externalizing the metal rotation process, eChem might enable students with low spatial abilities to rotate and visualize chemical compounds.

Any opinions, findings, and conclusions expressed in this study are those of the authors and do not necessarily reflect the views of the National Science Foundation. The authors wish to thank Brian Coppola, Barbara Hug, Elena Takaki, and Valerie Talsma for their comments on an early version of the manuscript. The authors also wish to thank the teachers and students who participated in this study.

\section{Notes}

${ }^{1} \mathrm{eChem}$ and its tutorial materials are available at http://hi-ce.org/sciencelaboratory/eChem

${ }^{2}$ Chime version 2.0a for Macintosh PowerPC, Copyright (C) 1996-1998 MDL Information Systems, Inc.

${ }^{3}$ Compared with physical and virtual reality models created by professional tools, eChem models are not truly three dimensional. Yet the eChem model shares four depth cues-an overlap cue, a relative size cue, a foreshortened line, and distortion of angles (Seddon \& Eniaiyeju, 1986) - as 3-D objects presented by 2 -D media, so throughout this article we have chosen to describe eChem model as 3-D with the recognition of its virtuality.

${ }^{4}$ Pseudonyms that maintain gender are used for teachers and students throughout this article.

\section{References}

Barnea, N., \& Dori, Y.J. (1996). Computerized molecular modeling as a tool to improve chemistry teaching. Journal of Chemical Information and Computer Science, 36, 629-636.

Barnea, N., \& Dori, Y.J. (1999). High-school chemistry students' performance and gender differences in a computerized molecular modeling learning environment. Journal of Science Education and Technology, 8(4), 257-271. 
Ben-Zvi, R., Eylon, B., \& Silberstein, J. (1986). Is an atom of copper malleable? Journal of Chemical Education, 63, 64-66.

Ben-Zvi, R., Eylon, B., \& Silberstein, J. (1987). Students' visualization of a chemical reaction. Education in Chemistry, July, 117-120.

Ben-Zvi, R., Eylon, B., \& Silberstein, J. (1988). Theories, principles and laws. Education in Chemistry, May, 89-92.

Berger, C., Walton, C., Jones, T., \& Wurman, P. (1995). The Event Recorder (Version 5.6). Ann Arbor, MI: The University of Michigan.

Brown, A.L. (1992). Design experiments: Theoretical and methodological challenges in creating complex interventions in classroom setting. Journal of Learning Sciences, 2, $141-178$.

Carter, C.S., LaRussa, M.A., \& Bodner, G.M. (1987). A study of two measures of spatial ability as predictors of success in different levels of general chemistry. Journal of Research in Science Education, 24(7), 645-657.

Clark, J.M., \& Paivio, A. (1991). Dual coding theory and education. Educational Psychology Review, 3, 149-210.

Copolo, C.F., \& Hounshell, P.B. (1995). Using three-dimensional models to teach molecular structures in high school chemistry. Journal of Science Education and Technology, 4(4), 295305.

Collins, A. (1999). The changing infrastructure of education research. In E.C. Lagemann \& L.S. Shulman (Eds.), Issues in Education Research: Problems and Possibilities (pp. 289-298). San Francisco: Jossey-Bass Publishers.

Crouch, R.D., Holden, M.S., \& Samet, C. (1996). CAChe molecular modeling: A visualization tool early in the undergraduate chemistry curriculum. Journal of Chemical Education, 73(10), 916-918.

Erickson, F. (1986). Qualitative methods in research on teaching. In M.C. Wittroc (Ed.), Handbook of research on teaching (3rd ed., pp. 119-161). New York: Macmillan Press.

Gabel, D. (1998). The complexity of chemistry and implications for teaching. In B.J. Fraser \& K.G. Tobin (Eds.), International handbook of science education (pp. 233-248). Boston, MA: Kluwer Academic Publishers.

Gabel, D., \& Sherwood, R. (1980). The effect of student manipulation of molecular models on chemistry achievement according to Piagetian level. Journal of Research in Science Teaching, 17(1), 75-81.

Gabel, D.L., Samuel, K.V., \& Hunn, D. (1987). Understanding the particulate nature of matter. Journal of Chemical Education, 64, 695-697.

Griffiths, A.K., \& Preston, K.R. (1992). Grade-12 students' misconceptions relating to fundamental characteristics of atoms and molecules. Journal of Research in Science Teaching, 29(6), 611-628.

Harrison, A., \& Treagust, D. (1996). Secondary students' mental models of atoms and molecules: Implications for teaching chemistry. Science Education, 80(5), 509-534.

Harrison, A.G., \& Treagust, D.F. (2000). Learning about atoms, molecules, and chemical bonds: A case study of multiple-model use in grade 11 chemistry. Science Education, 84, 352381.

Heubel-Drake, M., Finkel, L., Stern, E., \& Mouradian, M. (1995). Planning a course for success. The Science Teacher, 62, 18-21.

Hoffmann, R., \& Laszlo, R. (1991). Representation in chemistry. Angewandte Chemie, 30, $1-16$. 
Jackson, S., Krajcik, J.S., \& Soloway, E. (1998). The design of guided learner-adaptable scaffolding in interactive learning environments. Paper presented at the Human Factors in Computing Systems: CHI '98 Conference proceedings, Los Angeles.

Johnstone, A.H. (1993). The development of chemistry teaching. Journal of Chemical Education, 70(9), 701-705.

Johnstone, A.H., \& Letton, K.M. (1990). Investigating undergraduate lab work. Education in Chemistry, 28, 81-83.

Keig, P.F., \& Rubba, P.A. (1993). Translation of representations of the structure of matter and its relationship to reasoning, gender, spatial reasoning, and specific prior knowledge. Journal of Research in Science Teaching, 30(8), 883-903.

Kozma, R.B. (2000). Students collaborating with computer models and physical experiments. In C. Hoadley (Ed.), Computer support for collaborative learning (pp. 314322). Mahwah, NJ: Erlbaum Associates.

Kozma, R.B., Chin, E., Russell, J., \& Marx, N. (2000). The roles of representations and tools in the chemistry laboratory and their implications for chemistry instruction. Journal of the Learning Sciences, 9(2), 105-143.

Kozma, R.B., \& Russell, J. (1997). Multimedia and understanding: Expert and novice responses to different representations of chemical phenomena. Journal of Research in Science Teaching, 34, 949-968.

Kozma, R.B., Russell, J., Jones, T., Marx, N., \& Davis, J. (1996). The use of multiple, linked representations to facilitate science understanding. In R.G.S. Vosniadou, E. DeCorte, \& H. Mandel (Eds.), International perspective on the psychological foundations of technology-based learning environments (pp. 41-60). Hillsdale, NJ: Erlbaum.

Krajcik, J.S. (1991). Developing students' understanding of chemical concepts. In S.M. Glynn, R.H. Yeany, \& B.K. Britton (Eds.), The psychology of learning science: International perspective on the psychological foundations of technology-based learning environments (pp. 117-145). Hillsdale, NJ: Erlbaum.

Krajcik, J.S., Simmons, P.E., \& Lunetta, V.N. (1988). A research strategy for the dynamic study of students' concepts and problem solving strategies using science software. Journal of Research in Science Teaching, 25(2), 147-155.

Lesh, R., Post, T., \& Behr, M. (1987). Representations and translation among representations in mathematics learning and problem solving. In C. Janvier (Ed.), Problems of representation in the teaching and learning of mathematics (pp. 33-40). Hillsdale, NJ: Lawrence Erlbaum Associates.

Marx, R.W., Blumenfeld, P.C., Krajcik, J.S., \& Soloway, E. (1997). Enacting project-based science. Elementary School Journal, 97(4), 4-13, 22.

Mayer, R.E., \& Anderson, R.B. (1992). The instructive animation: Helping students build connections between words and pictures in multimedia learning. Journal of Educational Psychology, 84, 444-452.

Narayanan, H.N., \& Hegarty, M. (1998). On designing comprehensible interactive hypermedia manuals. International Journal of Human-Computer Studies, 48, 267-301.

Nye, M.J. (1993). From chemical philosophy to theoretical chemistry. Berkeley, CA: University of California Press.

O'Connor, E.A. (1997). Students' use of atomic and molecular models in learning chemistry. Unpublished dissertation, University at Albany, State University of New York.

Paivio, A. (1986). Mental representations: A dual-coding approach. New York: Oxford University Press. 
Perkins, D.N., Crismond, D., Simmons, R., \& Unger, C. (1995). Inside understanding. In J.L.S.D.N. Perkins, M.M. West, \& M.S. Wiske (Eds.), Software goes to school: Teaching for understanding with new technologies (pp. 70-91). New York: Oxford University Press.

Pribyl, J.R., \& Bodner, G.M. (1987). Spatial ability and its role in organic chemistry: A study of four organic courses. Journal of Research in Science Education, 24(3), 229-240.

Salomon, G. (1979). Interaction of media, cognition and learning. San Diego, CA: Jossey Bass.

Seddon, G.M., \& Eniaiyeju, P.A. (1986). The understanding of pictorial depth cues, and the ability to visualize the rotation of three-dimensional structures in diagrams. Research in Science and Technological Education, 4(1), 29-37.

Shubbar, K.E. (1990). Learning the visualization of rotations in diagrams of three dimensional structures. Research in Science and Technological Education, 8(2), 145-154.

Soloway, E., Guzdial, M., \& Hay, K.E. (1994). Learner-centered design: The challenge for human computer interaction in the 21st century. Interactions, 1, 36-48.

Soloway, E., Jackson, S.L., Klein, J., Quintana, C., Reed, J., Spitulnik, J., Stratford, S.J., Studer, S., Eng, J., \& Scala, N. (1996). Learning theory in practice: Case studies of learnercentered design. Paper presented at the Human Factors in Computing Systems: CHI '96 Conference proceedings, Vancouver, British Columbia.

Talley, L. (1973). The use of three-dimensional visualization as a moderator in the higher cognitive learning of concepts in college level chemistry. Journal of Research in Science Education, 10(3), 263-269.

Tuckey, H., Selvaratnam, M., \& Bradley, J. (1991). Identification and rectification of student difficulties concerning three-dimensional structures, rotation, and reflection. Journal of Chemical Education, 68(6), 460-464.

Williamson, V.M., \& Abraham, M.R. (1995). The effects of computer animation on the particulate mental models of college chemistry students. Journal of Research in Science Teaching, 32, 521-534. 